SHORT REPORT

\title{
Identification of novel MUNC13-4 mutations in familial haemophagocytic lymphohistiocytosis and functional analysis of MUNC13-4-deficient cytotoxic T lymphocytes
}

\author{
K Yamamoto, E Ishii, M Sako, S Ohga, K Furuno, N Suzuki, I Ueda, M Imayoshi, S Yamamoto, \\ A Morimoto, H Takada, T Hara, S Imashuku, T Sasazuki, M Yasukawa
}

Background: Familial haemophagocytic lymphohistiocytosis (FHL) has an autosomal recessive mode of inheritance and consists of at least three subtypes. FHL2 subtype with perforin (PRF1) mutation accounts for $30 \%$ of all FHL cases, while $\mathrm{FHL}$ with MUNC13-4 mutation was recently identified and designated as FHL3 subtype.

Objective: To examine MUNC13-4 mutations and the cytotoxic function of MUNC13-4 deficient T lymphocytes in Japanese FHL patients

Methods: Mutations of MUNC13-4 and the cytotoxicity of MUNC13-4-deficient cytotoxic T lymphocytes (CTL) were analysed in 16 Japanese families with non-FHL2 subtype.

Results: Five new mutations of the MUNC13-4 gene were identified in six families. The mutations were in the introns 4, 9, and 18, and exons 8 and 19. Two families had homozygous mutations, while the remaining four had compound heterozygous mutations. Cytotoxicity of MUNC13-4 deficient CTL was low compared with control CTL, but was still present. Clinically, the onset of disease tended to occur late; moreover, natural killer cell activity was not deficient in some FHL3 patients.

Conclusions: MUNC13-4 mutations play a role in the development of FHL3 through a defective cytotoxic pathway.

$\mathrm{H}$ aemophagocytic lymphohistiocytosis is characterised by fever, hepatosplenomegaly associated with pancytopenia, hypertriglyceridaemia, and hypofibrinogenaemia. ${ }^{12}$ Familial haemophagocytic lymphohistiocytosis (FHL) has an autosomal recessive mode of inheritance and usually occurs in infancy. ${ }^{3}$ The pathogenesis of FHL has been associated with impairment of the cytotoxic pathway in lymphocytes, where uncontrolled activation of T lymphocytes results in raised levels of inflammatory cytokines.

With regard to the genetic defect in FHL, linkage analyses have indicated possible loci in 9q21.3-22, designated FHLl (MIM 603552), and 10q21-22, designated FHL2 (MIM $603553) .{ }^{56} \mathrm{~A}$ mutation in the perforin gene (PRFI) was established as a cause of FHL2 in 1999. ${ }^{7-10}$ More recently, a mutation of MUNC13-4 mapped to 17q25 was identified as a causative gene of FHL3. ${ }^{11}$ The MUNC13-4 mutation leads to defective cytotoxic granule exocytosis followed by impaired cytotoxic activity of T lymphocytes in FHL3 patients. ${ }^{1}$

In this study we examined MUNC13-4 mutations and the cytotoxic function of MUNC13-4 deficient T lymphocytes in Japanese FHL patients.

\section{METHODS}

Sixteen unrelated families with non-FHL2 (no mutation in $P R F 1)$ were eligible for the detection of MUNC13-4 mutations.
All patients fulfilled the diagnostic criteria of HLH. ${ }^{2}$ Twelve of the 16 families had a positive family history, but consanguinity was noted in only one family. After informed consent had been obtained, genomic DNA and RNA were isolated from peripheral blood mononuclear cells. Samples from 62 healthy subjects were used as controls. In a comparative study of alloantigen specific $\mathrm{CD}^{+}$and $\mathrm{CD}^{+}$cytotoxic $\mathrm{T}$ lymphocytes (CTL), blood specimens were obtained from FHL2 and non-FHL2 patients as well as from their parents. The study was approved by the institutional review board at both Kyushu University and Saga University.

Genotyping of microsatellite markers was conducted as described earlier. ${ }^{12}{ }^{13}$ Four microsatellite markers adjacent to MUNC13-4 (D17S1807, D17S1603,D17S785, and D17S937) were amplified using fluorescent labelled primers. Electrophoresis of polymerase chain reaction (PCR) products was effected on an ABI3100 DNA sequencer (PE-Applied Biosystems, Norwalk, Connecticut, USA). Analyses and assignment of marker alleles were carried out using Genotyper software (PE-Applied Biosystems). For the detection of MUNC13-4 mutation, 28 primer sets were designed employing the Primer3 program (Whitehead Institute for Biomedical Research, Cambridge, Massachusetts, USA) to amplify the 32 exons and flanking intronic sequences of MUNC13-4 gene from genomic DNA. These PCR products were used for sequence analysis with ABI3100 or ABI3730 DNA sequencer (PE-Applied Biosystems). Mutations are numbered according to GenBank XM_113950; additionally, the A of the ATG initiator codon is defined as nucleotide +1 . Expression of MUNC13-4 was analysed by reverse transcriptase PCR. The PCR primers were designed to detect splicing variants generated by each mutation. PCR products were cloned into TA cloning vector (Invitrogen, San Diego, California, USA) and the sequences were verified on ABI3100 DNA sequencer.

Cytotoxic activities of alloantigen specific $\mathrm{CD}^{+}$and $\mathrm{CD}^{+}$ CTLs were determined as shown previously. ${ }^{14}{ }^{15}$ Peripheral blood mononuclear cells were obtained from the patients with MUNC13-4 deficiency ( $\mathrm{MUNC}^{-/-}$) and their parents $\left(\mathrm{MUNC}^{+/-}\right)$, as well as from normal controls. These cells were co-cultured with a mitomycin $\mathrm{C}$ treated B lymphoblastoid cell line (B-LCL) established from an HLA mismatched individual. Magnetisable polystyrene beads coated with anti-CD4 or anti-CD8 monoclonal antibody (Dynal, Oslo, Norway) were used to isolate $\mathrm{CD}^{+}$and $\mathrm{CD}^{+} \mathrm{T}$ lymphocytes, respectively, from peripheral blood mononuclear cells that had been stimulated with allogeneic B-LCL for six days. CD4 ${ }^{+}$ and $\mathrm{CD}^{+} \mathrm{T}$ lymphocytes, which were cultured in medium

Abbreviations: B-LCL, B lymphoblastoid cell line; CTL, cytotoxic T lymphocytes; FHL, familial haemophagocytic lymphohistiocytosis; HLA, human leucocyte antigen 
A

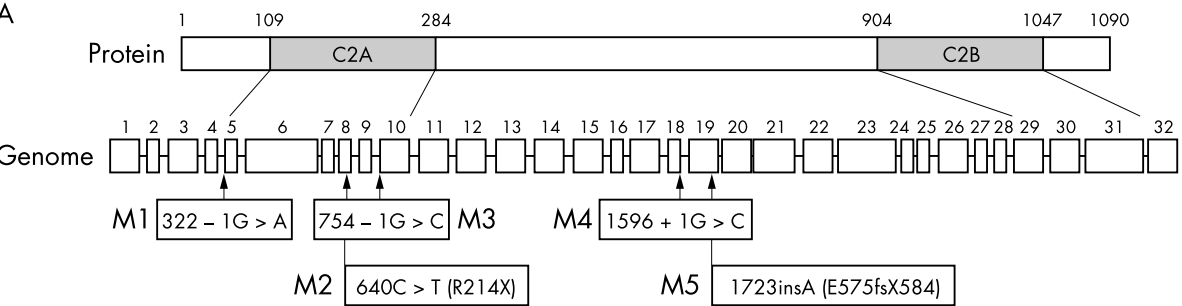

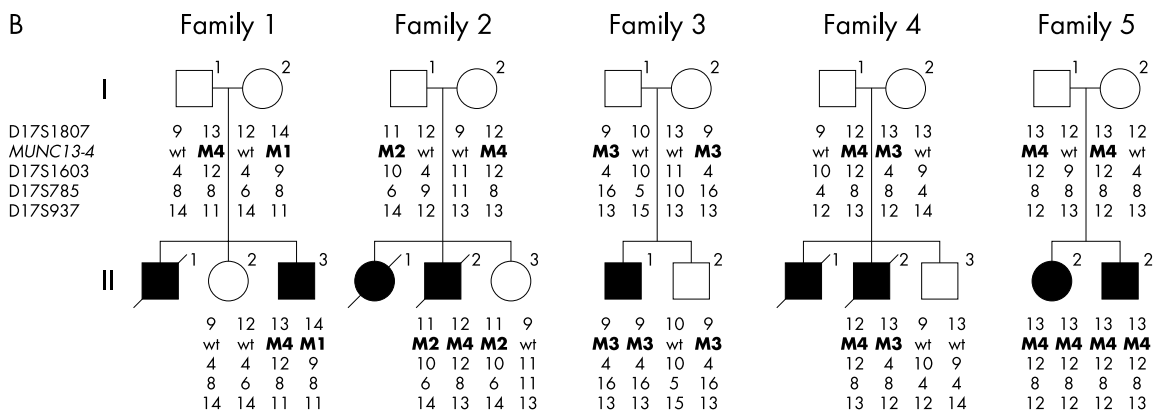

Figure 1 Identification of MUNC13-4 mutations associated with familial haemophagocytic lymphohistiocytosis (FHL). (A) Schematic representation of the MUNC13-4 protein and corresponding genomic organisation of the MUNC13-4 gene. The positions of two C2 domains (C2A and C2B) are indicated by amino acid number. The mutations $322-1 \mathrm{G} \rightarrow \mathrm{A}, 640 \mathrm{C} \rightarrow \mathrm{T}, 754-1 \mathrm{G} \rightarrow \mathrm{C}, 1596+1 \mathrm{G} \rightarrow \mathrm{C}$, and 1723insA identified in this study are designated $M 1, M 2, M 3, M 4$, and $M 5$, respectively. Nucleotides are numbered from $A$ of the initiation codon (ATG); $X$, stop; ins, insertion; $f_{s}$, frame shift. (B) Haplotype analysis of MUNC13-4 variants and microsatellite markers adjacent to MUNC13-4 in the five families characterised by FHL. The markers were ordered according to the Genome Browser of UCSC Genome Bioinformatics (http://genome.ucsc.edu/index.html). The pedigree of family 6 is not shown in this figure. Wt, no mutation.
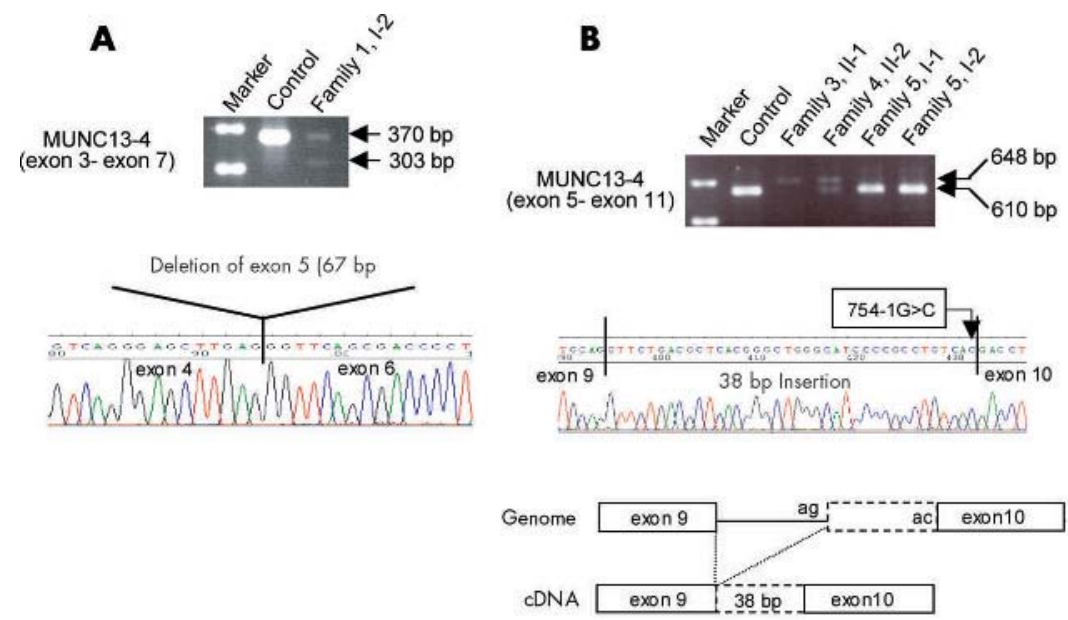
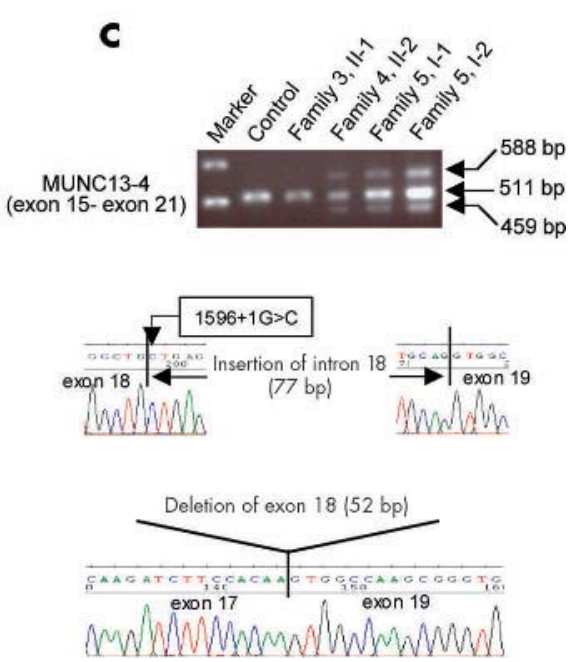

Figure 2 Reverse transcriptase polymerase chain reaction (RT-PCR) analysis of MUNC13-4 in patients with familial haemophagocytic lymphohistiocytosis (FHL). (A) Outcome of 322-1G $\rightarrow$ A mutation of MUNC13-4. A 370 base pair (bp) RT-PCR product of MUNC13-4 exons 3-7 was detected in control (lane 2) and family 1-I-2 (heterozygote for this mutation; lane 3), whereas an extra 303 bp product was detected exclusively in family 1-1-2 (lane 3). Sequence analysis of a $303 \mathrm{bp}$ fragment revealed that 322-1G $\rightarrow$ A caused skipping of exon 5 (67 bp), resulting in frame shift and translational arrest after an additional 14 amino acids. (B) Outcome of 754-1G $\rightarrow$ C mutation of MUNC13-4. A 610-bp RT-PCR product of MUNC13-4 exons 5-11 was detected in control (lane 2), family 4-II-2 (heterozygous for this mutation, lane 4), and in family 5-I-1 and -2, who do not carry this mutation (lanes 5 and 6). An extra 648 bp product was detected in family 3-II-1 (homozygous for this mutation) and family 4-II-2 (lanes 3 and 4). Sequence analysis of a 648 bp fragment revealed that the 754-1G $\rightarrow$ C mutation retains 38 bp of intron 9 in the cDNA; moreover, this insertion was generated by activation of a nearby cryptic splice acceptor site. This insertion is predicted to cause translational arrest after an additional 88 amino acids. (C) Outcome of 1596+1G $\rightarrow$ C mutation of MUNC13-4. A 51 1-bp RT-PCR product of MUNC13-4 exons 15-21 was detected in all samples carrying at least one MUNC13-4 gene without the 1596+1G $\rightarrow$ C mutation. Two additional products (588 and 459 bp) were detected in family 4-II-2, $5-1-1$ and -2 , which are heterozygous for this mutation (lane 4-6). Sequence analysis of a 588 bp product revealed that the 1596+1G $\rightarrow$ C mutation retains the entire intron $18(77 \mathrm{bp})$ in the cDNA. This $77 \mathrm{bp}$ insertion is predicted to cause translational arrest after an additional 40 amino acids. Sequence analysis of a 459 bp product showed that this mutation caused skipping of exon 18 (52 bp), resulting in frame shift and translational arrest after an additional 15 amino acids. 
with interleukin-2 (Genzyme, Boston, Massachusetts, USA), were stimulated with allogeneic B-LCL three times at one week intervals; subsequently, these lymphocytes served as effector cells. Cytotoxic activity was determined using a five hour ${ }^{51} \mathrm{Cr}$ release assay. To evaluate the role of perforin in CTL mediated cytotoxicity, effector cells were pretreated with an inhibitor of the perforin based cytotoxic pathway, concanamycin A (CMA) (Wako Pure Chemical Industries, Osaka, Japan), at a concentration of $100 \mathrm{nM}$ for two hours before incubation with target cells.

\section{RESULTS}

Five different sequence alterations were identified in six of 16 non-FHL2 families; these alterations were neither detectable in control subjects nor in a previous report which described six mutations, including 274delC (exon 3), 753+l G $\rightarrow \mathrm{T}$ (intron 9), C766T (exon 10), 1389+1G $\rightarrow$ A (intron 15), 1755inst (exon 20), and 1822dell2 bp (exon 20) in seven families. ${ }^{11}$ Mutations identified in this study were in introns 4,9 , and 18, and in exons 8 and 19, which included a nonsense change $(640 \mathrm{C} \rightarrow \mathrm{T}$, resulting in $\mathrm{R} 214 \mathrm{X})$, a single base insertion (1723insA, resulting in E575fsX584), an alteration occurring at the splice donor site $(1596+1 \mathrm{G} \rightarrow \mathrm{C})$, and aberrations at the splice acceptor sites $(322-1 \mathrm{G} \rightarrow \mathrm{A}$ and $754-$ $\mathrm{IG} \rightarrow \mathrm{C}$ ). Two families had homozygous aberrations (families 3 and 5) while the remaining four had compound heterozygous abnormalities (fig 1A and 1B). An interval of $2.3 \mathrm{Mb}$ between D17S1807 and D17S785 was homozygous in two families (one with the 754- $\mathrm{GG} \rightarrow \mathrm{C}$ allele (family 3 ) and one with the $1596+1 \mathrm{G} \rightarrow \mathrm{C}$ allele (family 5 )), although they were not consanguineous. In addition, families 2 and 4 shared a common haplotype for the $1596+1 \mathrm{G} \rightarrow \mathrm{C}$ allele, suggesting a common founder (fig 1B). The patient of family 6 was compound heterozygous for $1596+1 \mathrm{G} \rightarrow \mathrm{C}$ and 1723insA. Because DNA samples of parents were not available, we could not determine the haplotype of microsatellite markers in family 6.

Expression of MUNC13-4 was analysed in four families carrying mutations at splice acceptor or donor sites. By sequencing, the $322-1 \mathrm{G} \rightarrow \mathrm{A}$ mutation in intron 4 resulted in skipping of exon 5 (67 bases) (fig 2A). This deletion caused a frame shift and translational arrest at the site with an additional 14 amino acids apart. The $754-1 \mathrm{G} \rightarrow \mathrm{C}$ mutation in intron 9 led to inclusion of the 38 bases flanked by a nearby cryptic splice acceptor site and exon 10 in cDNA (fig 2B). This 38 base insertion induced translational arrest at the site with additional 88 amino acids apart. The $1596+1 \mathrm{G} \rightarrow \mathrm{C}$ mutation in intron 18 generated two abnormal transcripts: the long form which incorporated the entire intron 18 (77 bases), and the short form in which exon 18 (52 bases) was skipped (fig 2C). In both cases, a premature stop codon appeared at the site with additional amino acids apart (40 and 15 amino acids in the long and short forms, respectively). As the truncated proteins generated by these mutations do not contain C2A and/or C2B domains which mediate $\mathrm{Ca}^{+}$
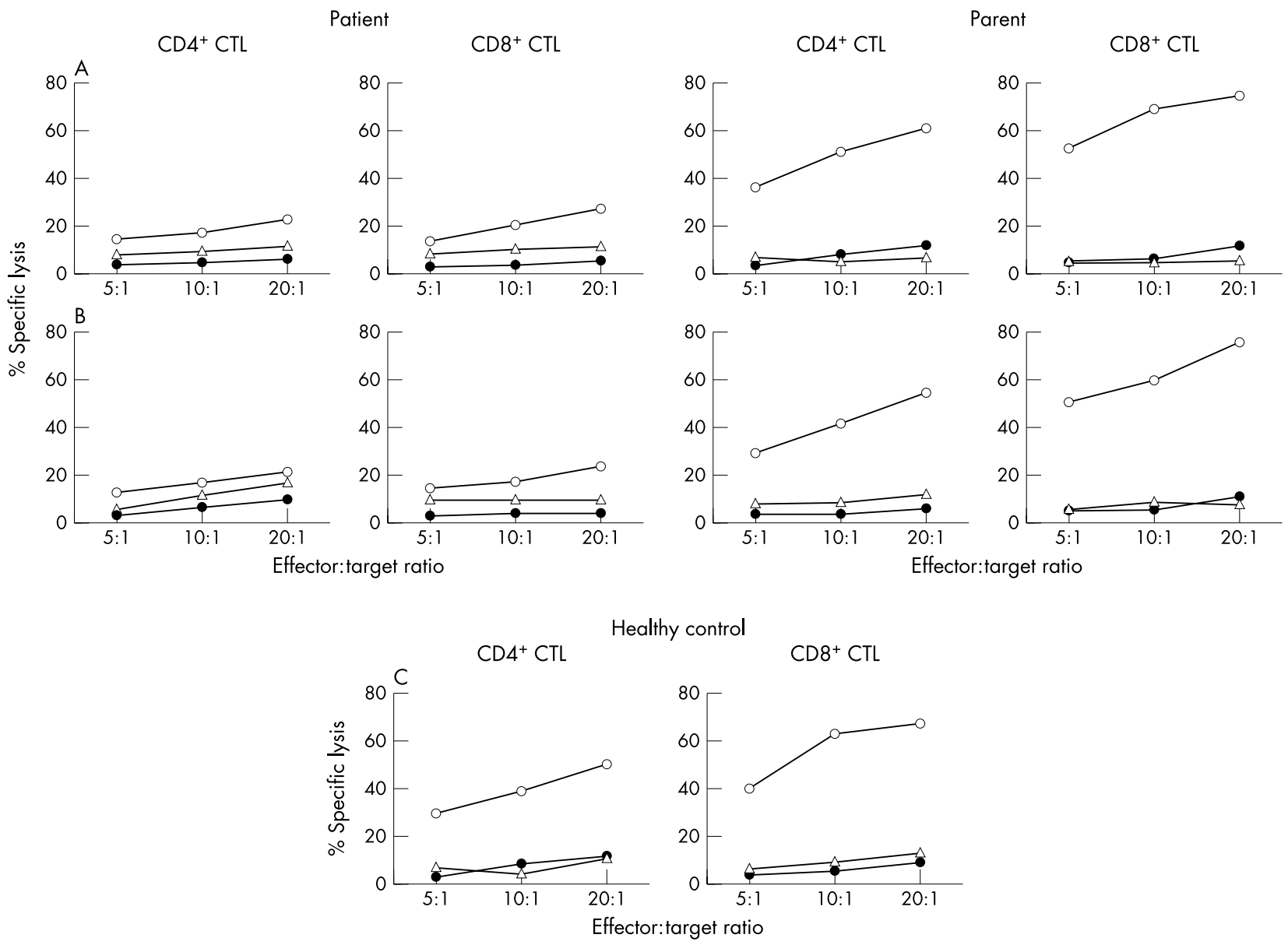

Figure 3 Cytotoxicity of alloantigen specific $\mathrm{CD} 4^{+}$and $\mathrm{CD} 8^{+}$cytotoxic T lymphocytes (CTL) generated from FHL3 families and a healthy control. (A) Family 3. (B) Family 4. CD4 $4^{+}$and $C D 8^{+}$CTL were derived from peripheral blood mononuclear cells obtained from patients, their healthy parents, and a healthy control by stimulation with allogeneic B lymphoblastoid cell line (B-LCL). Cytotoxicity of CTL pretreated with (triangles) or without (empty circles) CMA against allogeneic B-LCL and that of untreated CTL against autologous B-LCL (filled circles) was determined. 


\begin{tabular}{|c|c|c|c|c|c|c|c|}
\hline Family & Age/sex & $\begin{array}{l}\text { Family } \\
\text { history }\end{array}$ & $\begin{array}{l}\text { MUNC13-4 } \\
\text { mutations }\end{array}$ & $\begin{array}{l}\text { CNS } \\
\text { involvement }\end{array}$ & $\begin{array}{l}\text { NK } \\
\text { activity* }\end{array}$ & Treatment† & Outcome \\
\hline 1 & $11 \mathrm{mo} / \mathrm{M}$ & + & $\begin{array}{l}1596+1 G \rightarrow C \\
322-1 G \rightarrow A\end{array}$ & - & $29 \%$ & $\begin{array}{l}\text { VP16, CSA, PSL } \\
\text { ABMT }\end{array}$ & Alive \\
\hline 2 & $2 \mathrm{mo} / \mathrm{M}$ & + & $\begin{array}{l}640 \mathrm{C} \rightarrow \mathrm{T} \\
1596+1 \mathrm{G} \rightarrow \mathrm{C}\end{array}$ & - & $2.2 \%$ & VP16, CSA, PSL & Dead \\
\hline 3 & $6 \mathrm{mo} / \mathrm{M}$ & - & $\begin{array}{l}754-1 G \rightarrow C \\
754-1 G \rightarrow C\end{array}$ & + & $1-10 \%$ & $\begin{array}{l}\text { VP16, CSA, PSL } \\
\text { UCBT }\end{array}$ & Alive \\
\hline 4 & $5 \mathrm{mo} / \mathrm{M}$ & + & $\begin{array}{l}1596+1 G \rightarrow C \\
754-1 G \rightarrow C\end{array}$ & - & $1-19 \%$ & $\begin{array}{l}\text { VP16, CSA, PSL } \\
\text { UBMT }\end{array}$ & Dead \\
\hline 5 & $6 \mathrm{mo} / \mathrm{F}$ & + & $\begin{array}{l}1596+1 G \rightarrow C \\
1596+1 G \rightarrow C\end{array}$ & - & $1-3.2 \%$ & $\begin{array}{l}\text { VP16, CSA, PSL } \\
\text { UCBT }\end{array}$ & Alive \\
\hline 6 & $5 \mathrm{mo} / \mathrm{M}$ & + & $\begin{array}{l}1596+1 \mathrm{G} \rightarrow C \\
1723 \text { ins } A\end{array}$ & + & $5-7 \%$ & $\begin{array}{l}\text { VP16, CSA, PSL } \\
\text { UBMT }\end{array}$ & Dead \\
\hline \multicolumn{8}{|c|}{$\begin{array}{l}\text { *Normal value }>5 \% \text { when effector to target ratio is } 20: 1 \text {. } \\
\text { †The combination of VP16, CSA, and PSL was used as the HLH94 protocol, as proposed by the Histiocyte Societ } \\
\text { ABMT, allogeneic bone marrow transplantation; CNS, central nervous system; CSA, cyclosporin A; F, female; } N \\
\text { male; mo, months; NK, natural killer cell; PSL, prednisolone; UBMT, unrelated bone marrow transplantation; UCB } \\
\text { unrelated cord blood transplantation; VP16, etoposide. }\end{array}$} \\
\hline
\end{tabular}

dependent phospholipid binding (fig 1A), ${ }^{11}$ partial or total lack of biological function of MUNC13-4 was predicted.

We also analysed the antigen specific cytotoxic activity of MUNC13-4 deficient CTLs in two FHL3 families (families 3 and 4). All alloantigen stimulated CTLs in the patients and their parents, as well as in healthy controls, produced large levels of interferon $\gamma$ (IFN $\gamma$ ) with stimulation of allogeneic BLCL; production of IFN $\gamma$ was significantly inhibited by either anti-HLA class II or class I monoclonal antibody. Cytotoxic activities mediated by MUNC13-4 deficient and normal CTLS specific for alloantigen are presented in fig 3. Cytotoxicity of MUNC13-4 deficient CTLs against allogeneic B-LCL obtained from FHL3 patients remained; however, cytotoxicity was low in comparison with that of normal CTLs from the parents of the patients and healthy controls.

\section{DISCUSSION}

To date, the FHL phenotype has been thought to be homogeneous and indistinguishable among various types of FHL. ${ }^{71}$ Clinical and laboratory findings of FHL3 patients are summarised in table 1. Relative to that observed in FHL2 patients, ${ }^{910}$ age at onset tended to occur late (after five months); in particular, four patients had low but detectable natural killer cell (NK) activity (>5\% when the effector to target ratio is 20:1). The incidence of central nervous system involvement was low (two patients) in comparison with a previous report. ${ }^{11}$ Late infancy onset and decreased but detectable NK function could be associated with residual cytotoxicities in MUNC13-4 deficient T lymphocytes.

For HLH patients without a family history, genetic analysis of PRFI and MUNC13-4 genes is beneficial for the diagnosis of FHL2 and FHL3 subtypes. We previously found PRF1 mutations in approximately $30 \%$ of HLH patients. ${ }^{90}$ In this study, we identified six FHL3 cases (37.5\%) among 16 nonFHL2 families in Japan, suggesting that FHL3 may also represent another 30\% of FHL cases in Japan. Previously, it was reported that the clinical outcome in FHL patients depends on the type of mutations and the cytotoxic function of $\mathrm{T}$ lymphocytes. ${ }^{16}$ Our preliminary results indicate that disease onset tends to occur late in the FHL3 subtype; additionally, NK activity and cytotoxic function are low but still present. Recently, we encountered two FHL2 patients characterised by teenage onset showing missense mutations of PRFI (unpublished data). Identification of candidate genes for FHLl or other subtypes is a major concern; thus future determination of precise genotype-phenotype association must facilitate understanding of the distinct molecular mechanisms involved in the development of various FHL subtypes.

\section{Data access}

Accession numbers and URLs for data presented herein are as follows:

- GenBank accession number: MUNC13-4 gene sequence, XM 113950.

- Whitehead Institute for Biomedical Research: http:// www.broad.mit.edu/ (for amplification of MUNC13-4 gene).

- The Genome Browser of UCSC Genome Bioinformatics: http://genome.ucsc.edu/index.html.

- The National Center for Biotechnology Information: http:// www.ncbi.nlm.nih.gov/ (for information of microsatellite markers).

\section{ACKNOWLEDGEMENTS}

We thank all patients and their family members who participated in this study. We also wish to thank all members of the Japan FHL study group. This work was supported by the Histiocyte Association of America and a grant-in-aid for scientific research and a grant from the 21 st COE Programme from the Ministry of Education, Culture, Sports, Science and Technology, Japan.

\section{Authors' affiliations}

K Yamamoto, K Furuno, Division of Molecular Population Genetics, Department of Molecular Genetics, Medical Institute of Bioregulation, and Kyushu University COE Programme on Lifestyle-Related Diseases, Kyushu University

E Ishii, M Imayoshi, S Yamamoto, Department of Paediatrics, Faculty of Medicine, Saga University, Saga, Japan

M Sako, Division of Paediatrics, Osaka City General Hospital, Osaka, Japan

S Ohga, H Takada, T Hara, Department of Paediatrics, Graduate School of Medical Sciences, Kyushu University, Kyushu, Japan

N Suzuki, Department of Paediatrics, Sapporo Medical University, Sapporo, Japan

I Ueda, S Imashuku, A Morimoto, Department of Paediatrics, Kyoto Prefectural University of Medicine, Kyoto, Japan

T Sasazuki, Research Institute, International Medical Centre of Japan, Tokyo, Japan

M Yasukawa, Department of 1st Internal Medicine, Ehime University, Ehime, Japan

Conflicts of interest: none declared

Correspondence to: Dr Eiichi Ishii, Department of Paediatrics, Faculty of Medicine, Saga University, 5-1-1 Nabeshima, Saga 849-8501, Japan; ishiei@med.saga-u.ac.jp 
Revised version received 10 May 2004

Accepted for publication 17 May 2004

\section{REFERENCES}

1 Loy TS, Diaz-Arias AA, Perry MC. Familial erythrophagocytic lymphohistiocytosis. Semin Oncol 1991;18:34-9.

2 Henter J, Elinder G, Ost A. Diagnostic guidelines for hemophagocytic lymphohistiocytosis. The FHL study group of the Histiocyte Society. Semin Oncol 1991; 18:29-33.

3 Filipovich AH. Hemophagocytic lymphohistiocytosis: a lethal disorder of immune regulation. J Pediatr 1997; 130:337-8.

4 Arico M, Danesino C, Pende D, Moretta L. Pathogenesis of haemophagocytic lymphohistiocytosis, Br J Haematol 2001:114:761-9.

5 Ohadi M, Lalloz MR, Sham P, Zhao J, Dearlove AM, Shiach C, Kinsey S, Rhodes $M$, Layton DM. Localization of a gene for familial hemophagocytic lymphohistiocytosis at chromosome 9q21.3-22 by homozygosity mapping. Am J Hum Genet 1999:64:165-71.

6 Dufourcq-Lagelouse R, Jabado N, Le Deist F, Stephan JL, Souillet G, Bruin M, Vilmer E, Schneider M, Janka G, Fischer A, de Saint Basile G. Linkage of familial hemophagocytic lymphohistiocytosis to 10q21-22 and evidence for heterogeneity. Am J Hum Genet 1999;64:172-9.

7 Stepp SE, Dufourcq-Lagelouse R, Le Deist F, Bhawan S, Certain S, Mathew PA Henter JI, Bennett M, Fischer A, de Saint Basile G, Kumar V. Perforin gene defects in familial hemophagocytic lymphohistiocytosis. Science 1999;286: 1957-9.

8 Goransdotter Ericson K, Fadeel B, Nilsson-Ardnor S, Soderhall C, Samuelsson A, Janka G, Schneider M, Gurgey A, Yalman N, Revesz T, Egeler R, Jahnukainen K, Storm-Mathiesen I, Haraldsson A, Poole J, de Saint Basile G, Nordenskjold $M$, Henter J. Spectrum of perforin gene mutations in familial hemophagocytic lymphohistiocytosis. Am J Hum Genet $2001 ; 68: 590-7$

9 Suga N, Takada H, Nomura A, Ohga S, Ishii E, Ihara K, Oshima K, Hara T. Perforin defects of primary haemophagocytic lymphohistiocytosis in Japan. Br J Haematol 2002; 116:346-9.
10 Ueda I, Morimoto A, Inaba T, Yagi T, Hibi S, Sugimoto T, Sako M Yanai F, Fukushima T, Nakayama M, Ishii E, Imashuku S. Characteristic perforin gene mutations of haemophagocytic lymphohistiocytosis patients in Japan. Br J Haematol 2003;121:503-10.

11 Feldmann J, Callebaut I, Raposo G, Certain S, Bacq D, Dumont C, Lambert N, Ouachee-Chardin M, Chedeville G, Tamary H, Minard-Colin V, Vilmer E, Blanche S, Le Deist F, Fischer A, de Saint Basile G. Munc13-4 is essential for cytolytic granules fusion and is mutated in a form of familial hemophagocytic lymphohistiocytosis (FHL3). Cell 2003;115:461-73.

12 Sakai K, Shirasawa S, Ishikawa N, Ito K, Tamai H, Kuma K, Akamizu T, Tanimura M, Furugaki K, Yamamoto K, Sasazuki T. Identification of susceptibility loci for autoimmune thyroid disease to 5 q31-q33 and Hashimoto's thyroiditis to 8 q23-q24 by multipoint affected sib-pair linkage analysis in Japanese. Hum Mol Genet $2001 ; 10: 1379-86$

13 Miyoshi Y, Yamada T, Tanimura M, Taniwaki T, Arakawa K, Ohyagi Y, Furuya $\mathrm{H}$, Yamamoto K, Sakai K, Sasazuki T, Kira J. A novel autosomal dominant spinocerebellar ataxia (SCA16) linked to chromosome 8q22.124.1. Neurology 2001;57:96-100.

14 Yasukawa M, Ohminami H, Arai J, Kasahara Y, Ishida Y, Fujita S. Granule exocytosis, and not the fas/fas ligand system, is the main pathway of cytotoxicity mediated by alloantigen-specific CD4(+) as well as CD8(+) cytotoxic T lymphocytes in humans. Blood 2000:95:2352-5

15 Yanai F, Ishii E, Kojima K, Hasegawa A, Azuma T, Hirose S, Suga N Mitsudome A, Zaitsu M Ishida Y, Shirakata Y, Sayama K, Hashimoto K, Yasukawa M. Essential roles of perforin in antigen-specific cytotoxicity mediated by human CD4+ T lymphocytes: analysis using the combination of hereditary perforin-deficient effector cells and Fas-deficient target cells. J Immunol 2003; 170:2205-12

16 Schneider EM, Lorenz I, Muller-Rosenberger M, Steinbach G, Kron $M$, Janka-Schaub GE. Hemophagocytic lymphohistiocytosis is associated with deficiencies of cellular cytolysis but normal expression of transcripts relevant to killer-cell-induced apoptosis. Blood 2002;100:2891-8 